Review

\title{
Advances in Electronic-Nose Technologies for the Detection of Volatile Biomarker Metabolites in the Human Breath
}

\author{
Alphus D. Wilson \\ Southern Hardwoods Laboratory, Center for Bottomland Hardwoods Research, Southern Research \\ Station, USDA Forest Service, P.O. Box 227, Stoneville, MS 38776, USA; E-Mail: dwilson02@fs.fed.us; \\ Tel.: +1-662-686-3180; Fax: +1-662-686-3195 \\ Academic Editor: Jörg Ingo Baumbach
}

Received: 29 December 2014 / Accepted: 23 February 2015 / Published: 2 March 2015

\begin{abstract}
Recent advancements in the use of electronic-nose (e-nose) devices to analyze human breath profiles for the presence of specific volatile metabolites, known as biomarkers or chemical bio-indicators of specific human diseases, metabolic disorders and the overall health status of individuals, are providing the potential for new noninvasive tools and techniques useful to point-of-care clinical disease diagnoses. This exciting new area of electronic disease detection and diagnosis promises to yield much faster and earlier detection of human diseases and disorders, allowing earlier, more effective treatments, resulting in more rapid patient recovery from various afflictions. E-nose devices are particularly suited for the field of disease diagnostics, because they are sensitive to a wide range of volatile organic compounds (VOCs) and can effectively distinguish between different complex gaseous mixtures via analysis of electronic aroma sensor-array output profiles of volatile metabolites present in the human breath. This review provides a summary of some recent developments of electronic-nose technologies, particularly involving breath analysis, with the potential for providing many new diagnostic applications for the detection of specific human diseases associated with different organs in the body, detectable from e-nose analyses of aberrant disease-associated VOCs present in air expired from the lungs.
\end{abstract}

Keywords: artificial olfaction; biomarker indicator compounds; breath gas analysis; breathprints; disease diagnostics; electronic aroma detection; e-nose; metabolomics; respiratory gas metabolites; volatile organic compounds 


\section{Introduction}

Traditional methods for the detection and diagnosis of diseases are often invasive and expensive or require time-consuming biological (culturing), microscopic (cell or tissue biopsy) or complex analytical (chemical) tests. Some conventional methods used in clinical diagnoses include many invasive and potentially hazardous biopsy procedures, endoscopy [1], computed tomography [2], DNA marker and homology tests, magnetic resonance imaging (MRI) [3], mammography [4], microbial culture tests, positron emission tomography (PET) [5], serological and other blood tests, ultrasonography [6] and X-ray imaging of other organs [7]. Many of these methods not only present some risks of serious negative side effects, but often are sufficiently painful to discourage patients from participating in preemptive, prophylactic disease-screening procedures. These human-sentiment factors continue to point to the increasing need for improvements in diagnostic methods toward more non-invasive and painless procedures in disease screenings for early diagnosis and for patient examinations and checkups in routine clinical practice.

The search for noninvasive methods of human disease diagnosis have led to the discovery of more rapid, electronic methods of detecting and analyzing complex gaseous mixtures containing volatile organic compounds (VOCs), including metabolites and abnormal chemicals that are specific indicators (biomarkers) of disease, released from the body directly in air expired from the lungs and body cavities or from the headspace of body fluids (blood, serum, sputum, urine, etc.) and soft tissue samples collected from sick patients during clinical examinations [8]. Electronic aroma detection (EAD) technologies encompass a wide array of electronic-nose (e-nose)-type technologies with many different gas-detection mechanisms and operating principles [9]. The many types of e-nose instruments range from surface acoustic wave (SAW), quartz crystal microbalance (QMB), metal oxide semiconducting (MOS) and conducting polymers (CP), to the newer DNA-carbon nanotubes [10], and many others [9].

Electronic-nose instruments have many advantages over traditional analytical tools used for chemical analyses, including being less expensive, ease of use and operation without extensive training required, rapid results and response time, quick sensor recovery time, excellent precision, low operating costs, smaller with greater portability and large flexibility in sensor array specificity for selective, specialized applications [9,11,12]. Some disadvantages of e-nose instruments are the inability to identify individual compounds in complex mixtures, sensor arrays sensitive to water vapor, relatively short sensor life, difficulty in measuring analyte concentrations accurately, somewhat lower sensitivity than analytical chemistry instruments and problems of sensor translation [9].

E-nose instruments offer potentially new, non-invasive, cost-effective (potentially inexpensive) approaches to clinical disease diagnosis by means of real-time VOC detection and analysis of exhaled breath samples. Nevertheless, the field of breath analysis research is just beginning and faces many challenges, mainly because the biochemical mechanisms behind the release of disease-related VOCs in the body are largely unknown, and therefore, the correlations between proposed biomarker metabolites and disease are still tenuous and require considerably more investigations.

This review will explore and summarize many of the emerging developments of e-nose technologies for human disease diagnosis, particularly in the more specific and specialized research field of breath analysis or metabolomics. Breath analysis is an area of disease diagnostics that is receiving increasing attention due to the great potential for the simultaneous noninvasive detection and diagnosis of diseases in all parts of the body, based on the production and release of abnormal metabolites (disease biomarkers) from point sources in tissues of individual organs, which are eventually released from the body through 
the human breath. Breath-associated exogenous biomarkers also are potential indicators of increased risk of future disease development in the body due to short-term or prolonged exposure to toxic or noxious fumes through inhalation.

\section{Biomarkers of Disease}

Disease-related biomarkers (as defined in medicine) are chemicals, usually VOCs, which indicate the presence or severity of a particular disease state or some abnormal physiological condition of an organism. A biomarker may be a chemical substance introduced into an organism (exogenous) or produced within the body (endogenous), which can be detected and measured in the blood, bodily fluids, tissues or human breath, and serves as an indicator of either normal or disease processes in the body. Biomarkers are useful for measuring the progress of disease, evaluating the most effective therapeutic treatments for a particular disease type and establishing long-term susceptibility to specific types of diseases. They are useful in early disease detection and diagnosis, disease prevention, drug target identification, drug response, determining probable effects of treatments on a patient (via risk indicator or predictive biomarkers), establishing if a disease already exists (diagnostic biomarker) and provide indications as to how a particular disease may develop in an individual case regardless of the type of treatment (prognostic biomarker). Predictive biomarkers facilitate the assessment of the most likely responses to a particular treatment type, while prognostic biomarkers show the progression of disease with or without treatment.

The precise definition of disease biomarkers varies somewhat with different researchers, particularly between those in different research fields. Some scientists include external (exogenous) sources of chemicals as biomarkers when they appear to be partially or wholly responsible for causing or inducing disease development in the body; while others limit the term to include only endogenous chemicals, abnormal VOC metabolites produced as a result of the disease process (pathogenesis) and, thus, bioindicators of a disease condition somewhere within the human body.

\subsection{Chemical Classes of Disease Biomarkers}

The first important consideration in deriving correlations between volatile metabolites and the biochemical processes associated with pathogenesis (disease processes) in the body from which they are derived is to determine which VOCs in the human breath can be considered the result of "normal" physiological processes and distinguish these from the "abnormal" VOCs that are produced as a result of disease processes. More than 2,000 VOCs have been identified in the human breath that can be considered normal [13], but even some of these volatiles can indicate a disease condition (somewhere in the body) if elevated or decreased concentrations are found in the breath. Some of the most common (normal) exhaled breath metabolites found in healthy individuals include the major atmospheric unmodified exogenous gases, such as nitrogen ( $72 \%$ by volume), oxygen (reduced from $21 \%$ inhaled to about $15 \%$ exhaled), carbon dioxide (about 5\%), water vapor (about 6\% at saturation) and argon (about 1\%) [14]. In addition to these major normal gases, other common endogenous VOCs include ammonia, acetone, ethanol, methanol, propanol, acetaldehyde and isoprene [15-20]. Ammonia was found to be a major breath metabolite, measured at a concentration of $833 \mathrm{ppb}$, followed by acetone (477 ppb), methanol (461 ppb), ethanol (112 ppb), isoprene (106 ppb), acetaldehyde (22 ppb) and propanol (18 ppb) [17-20]. 
A wide range of abnormal VOCs, discovered as possible biomarkers of various human diseases, are members of a large diversity of organic chemical classes. Some of the more common chemical classes to which disease biomarker VOCs belong include aliphatic hydrocarbons, aromatic hydrocarbons, alcohols, aldehydes, carboxylic acids (organic acids), esters, ethers, heterocyclic hydrocarbons, ketones, nitriles, sulfides and terpenoids or isoprenoids (terpenes and derivatives) [12]. Different classes of VOCs have many different physicochemical properties that largely determine their distribution, adverse effects and retention in the human body, as well as mechanisms and rates of release from the body in the breath or by other excretory means.

The physicochemical characteristics or chemical nature of disease biomarker VOCs also determine the best or most appropriate methods for detection and identification, either individually using analytical chemistry techniques or in complex mixtures in the human breath, which are best identified as collective aroma patterns, often referred to as breathprints, breath profiles or breath signatures.

\subsection{Origins of Disease Biomarkers}

The types and origins of biomarkers in the human breath are important for determining the sources and potential negative effects associated with the presence of specific VOCs in the body and for evaluating the diagnostic significance of breath biomarkers found (in terms of disease detection in the body), localization of pathogenic effects in specific organs or body compartments and the severity of disease development (as indicators of measurable stages of pathogenesis) or progress of the disease over time. In this way, repeated measures of biomarkers in the breath over time can indicate the rate of disease development and the duration of disease presence in the body.

\subsubsection{Physicochemical Characteristics of VOCs}

The partition coefficients of biomarker VOCs between blood and air $\left(\lambda_{b: a}\right)$ and between fat and blood $\left(\lambda_{\mathrm{f}: \mathrm{b}}\right)$ are used to estimate the equilibrium concentration of VOCs in the blood relative to exhaled air and in fat tissue relative to blood, respectively [12]. These partition coefficients, measured in dimensionless units, e.g., mol $\mathrm{Lb}^{-1} / \mathrm{mol} \mathrm{La}^{-1}$, largely determine the chemical characteristics of breath VOCs and the likelihood that a particular VOC is capable of existing in specific compartments of the body. As a result, lipophilic compounds of higher molecular weights or higher boiling points (BP) may occur at a low concentration $(\sim 1-2 \mathrm{ppb})$ in the exhaled breath, but be indicative of a relatively high concentration in the fat compartment due to lower volatility and greater solubility in blood that hinders out-gassing of these VOCs from the lung airways.

Breath gases with low solubility in blood, mainly nonpolar $\left(\lambda_{\mathrm{b}: \mathrm{a}}<10\right)$ compounds, undergo pulmonary gas exchange (PGE) almost exclusively in the alveoli, while VOCs that are well soluble in blood, primarily polar $\left(\lambda_{b: a}>100\right)$ compounds, tend to also exchange in the airways of the lungs [21-24]. Further studies of PGE have shown that VOCs with intermediate $\lambda_{b}$ a values between 10 and 100 are involved in exchanges in the airways and alveoli, suggesting that the airways may play a more significant role in PGE than previously believed. The breath VOC profile is influenced by the time of retention of VOCs in the lungs, the physicochemical properties of individual VOCs and their interactions with the various PGE processes $[25,26]$. 


\subsubsection{Exogenous VOCs}

Exogenous VOCs detected in the human breath have received much interest, because the presence of these chemicals may indicate prior exposure of an individual to toxic chemicals and possible carcinogens. Since exogenous VOCs are potentially direct indicators of exposure to disease-causing chemical agents (toxins, noxious or toxic fumes, etc.), their detection implies the possibility of adverse effects having occurred to the human body, not only in the form of diseases, but also physical damage to organs that can lead to organ dysfunctions or failures, metabolic disorders and significant tissue damage to lungs, brain and organ systems, particularly the circulatory and nervous systems. The presence of exogenous VOCs in the breath do not necessarily indicate the presence of disease or damage to the body, but only provide clues that disease or damage to organs is more probable and may be present. Therefore, individuals with exposure to these chemical are potentially at higher risk of a higher incidence of disease and are candidates for e-nose breath-analysis screenings to detect early stages of disease.

A large variety of trace exogenous gases exist in ambient air that is taken up via inhalation, skin absorption and through ingestion. The majority of these trace VOCs found in exhaled breath probably originate from exogenous sources and should be distinguished from endogenous compounds [15,27]. Exogenous VOCs can originate from a variety of point sources, such as from building fires, industrial and transportation-related air pollution, municipal air effluents (pollutants), toxic chemical spills and natural pollutants, such as sulfur dioxide and hydrogen sulfide from geothermal sources (volcanoes, hot springs and geysers), eutrophic swamps and bogs and mines open to the atmosphere. Exogenous VOCs are considered highly reactive and typically cause peroxidative damage to DNA, proteins and polyunsaturated fatty acids (PUFA) [12]. The negative impacts of exogenous VOCs on the body can accumulate over many years and result in chronic diseases and cancer [28]. Once exogenous lipophilic toxic VOCs are inhaled and pass from the lungs into the circulatory system, they may be stored within fat compartments of the body and eventually released to cause damage and disease for weeks or months after the initial exposure [29]. Most proposed cancer biomarkers are lipophilic and are reported to be stored in the fat compartment [12].

The levels of exogenous VOCs detected in the breath depend on many factors, including the ambient concentrations in inhaled air, the duration of exposure to ambient air, the solubility and partition coefficients of VOCs into tissues, the mass and fat content of individuals and endogenous concentration relative to blood concentrations. Schubert et al. [30] suggested that exhaled concentrations of specific exogenous VOCs cannot be confidently correlated with blood levels of the same compounds when inhaled (ambient) concentrations of exogenous compounds are greater than $5 \%$ of the exhaled concentrations. The concept of the alveolar gradient [31], defined as the abundance in breath minus ambient air, does not account for variable VOCs in inhaled background air, as demonstrated in numerous studies.

\subsubsection{Endogenous VOCs}

The normal endogenous VOCs found in human breath, largely derived from internal tissue sources as a result of human metabolism, such as inorganic gases (e.g., $\mathrm{CO}, \mathrm{CO} 2$ and $\mathrm{NO}$ ) and VOCs (isoprene, ethane, pentane, acetone, etc.) are detected and measured directly in the breath, while other, typically non-volatile substances (e.g., isoprostanes, peroxynitrite or cytokines) are measured in the breath condensate [32]. These non-volatile substances occur in exhaled breath as aerosol particles. 
Endogenous VOCs tend to be less reactive that exogenous VOCs and have a much lower tendency to be stored in the fat compartments of the body (due to their greater volatility). Endogenous VOCs also have a stronger tendency to be dissolved in the blood (high blood solubility due to greater polarity) for easier transport via the blood to the lungs for release through exhalation [33-36]. The physicochemical characteristics of higher polarity and shorter retention in the body make the endogenous VOCs more conducive to detection in the breath, more rapidly after formation, by use of electronic sensor arrays.

\section{Specificity of Disease-Associated Biomarkers}

Diseases of the human body can arise from several different major mechanisms having origins derived from genetic defects (such as metabolic disorders), short- or long-term exposure to exogenous abiotic toxins or teratogenic chemicals and through biotic agents (pathogens), generally involving a microbe capable of inducing states of pathogenesis by altering the normal biochemical and physiological processes of the host. Each of these disease-causing mechanisms produce and release different types of aberrant chemicals into the body that are characteristic of the particular disease mechanism and the specific microbes involved. Pathogenic microbes themselves also release unique combinations of volatile metabolite biomarkers in the body, which become part of the detectable VOC disease signatures associated with biotic causal agents. Many diseases affect only certain organs or organ systems in the body. This specificity of disease effects on certain organs largely determines the types of aberrant chemicals produced as a result of the specialized biochemical processes that occur in specific organs, the unique physiological pathways of the host that are altered and the peculiar metabolites that result from pathogenesis or altered genetic expressions of defective genes.

The unique mechanisms of disease and resulting abnormal chemicals produced by different types of human diseases result in the production and release of chemicals into affected tissues, regardless of their location in the body, which are picked up by the circulatory system and eventually exchanged and expelled through the lungs. As a consequence, the complex gaseous mixtures released from the lungs through the breath provide biochemical clues (useful for diagnoses) to all of the aberrant biochemical processes occurring simultaneously in the body, including diseases that may occur in any tissues or organs. The general overall health of an individual may, therefore, be measured and monitored on a continuous basis to determine changes in the healthful state of the body as a whole based on the presence or absence of specific biomarker breath compounds that have been associated, through empirical research, with specific diseases. Breath monitoring of patients following treatments can provide indications of the effectiveness of treatments, recovery from disease conditions and indications of the prognoses going forward.

\subsection{Biomarkers of Metabolic Diseases}

Metabolic diseases are physiological disorders, generally caused by inherited genetic defects, which often result in a deficiency or inadequate production of an enzyme or hormone (e.g., insulin) required for normal metabolic activities. Hundreds of different genetic-based metabolic disorders, related to a single missing enzyme, cause various symptoms depending on that enzyme's job, but usually cause the buildup of toxic metabolites that the deficient enzyme is responsible for converting to other essential products in anabolic or catabolic processes (biochemical pathways). 
Because metabolic diseases often involve the production of an excess or deficiency in a specific enzyme needed for the metabolism of certain amino acids, there is often only one very specific biomarker compound or several closely related compounds (from the same chemical class) detectable in the blood or expelled air that is indicative of a particular metabolic disease or disorder. This specific biomarker is usually the toxic metabolite that accumulates as a result of the enzyme deficiency. Some examples of single-compound biomarker indicators of specific metabolic-related diseases and microbial infections are presented in Table 1.

Table 1. Biomarker compounds in the human breath that appear to be uniquely associated with the presence of specific diseases, genetic disorders or adverse physiological conditions in the body.

\begin{tabular}{|c|c|c|c|}
\hline Biomarker Compounds ${ }^{1}$ & Chemical Class & $\begin{array}{c}\text { Associated Diseases/ } \\
\text { Disorders/Conditions }^{2}\end{array}$ & References \\
\hline 2,3-butanedione & diketone & URTI & [37] \\
\hline 2-butenal & aldehyde & URTI & [37] \\
\hline 2-butene & alkene & URTI & [37] \\
\hline 2-imidazoleacetic acid & imidazole & Histidinemia & [38] \\
\hline 2-imidazolelactic acid & imidazole & Histidinemia & [38] \\
\hline 2-imidazolepyruvic acid & imidazole & Histidinemia & [38] \\
\hline 2-oxoisocaproic acid & carboxylic acid & $\mathrm{BCKD}$ & [38] \\
\hline 2-pentylfuran & furan derivative & Aspergillosis (invasive) & [39] \\
\hline cadaverine & diamine & Cystinuria & {$[38,40]$} \\
\hline ethylbenzene & benzene derivative & Hyperglycemia & {$[41,42]$} \\
\hline formaldehyde & aldehyde & PLC & {$[43]$} \\
\hline methyl methacrylate & methyl ester & URTI & [37] \\
\hline methyl nicotinate & methyl ester & Tuberculosis & [44] \\
\hline phenylacetic acid & benzene derivative & Phenylketonuria & {$[38]$} \\
\hline phenyllactic acid & benzene derivative & Phenylketonuria & {$[38]$} \\
\hline phenylpyruvic acid & benzene derivative & Phenylketonuria & {$[38]$} \\
\hline p-hydroxyphenylpyruvic acid & benzene derivative & Tyrosinemia & [38] \\
\hline piperidine & heterocyclic amine & Cystinuria & {$[38,40]$} \\
\hline putrescine & diamine & Cystinuria & {$[38,40]$} \\
\hline pyrrolidine & heterocyclic amine & Cystinuria & {$[38,40]$} \\
\hline trans-3-methyl-2 hexenoic acid & fatty acid & SFS & {$[45]$} \\
\hline vinyl butyrate & vinyl ester & URTI & [37] \\
\hline xylene & dimethyl benzene & Hyperglycemia & {$[41,42]$} \\
\hline \multicolumn{4}{|c|}{$\begin{array}{l}{ }^{1} \text { Bio-indicator compounds listed are volatile organic compounds that have been associated with specific } \\
\text { diseases, metabolic disorders or adverse physiological conditions, but further independent research may be required } \\
\text { to determine the strength of the correlation based on the incidence of these bio-indicator VOCs in the human } \\
\text { breath relative to the presence of the indicated ailments. }{ }^{2} \text { Disease abbreviations: BCKD = branched-chain } \\
\text { ketoaciduria disorder (maple syrup urine disease); PLC = primary lung cancer; SFS = sweaty feet syndrome; }\end{array}$} \\
\hline
\end{tabular}

Other types of single metabolite-specific diseases also exist that are not caused by enzyme deficiencies, but hormone deficiencies, such as hyperglycemia (related to diabetes) and sweaty feet syndrome (SFS), that are correlated with specific biomarkers. Microbial infections, including upper 
respiratory tract infections (URTI), invasive aspergillosis and tuberculosis (caused by Mycobacterium tuberculosis infections), also have been related to the presence of single specific biomarkers.

\subsection{Biomarkers of Infectious Diseases}

A multitude of breath volatile metabolites have been identified as potential biomarkers of many infectious diseases and for cancer detection [8]. Some of these biomarkers associated with more than one infectious disease are listed in Table 2. The association of a specific biomarker to several types of diseases suggests that there may be some commonality to the effects of pathogenesis (associated with different diseases) that may result in similar alterations in biochemical pathways within the body to produce the same abnormal volatile metabolites in common between different and unrelated diseases. In some cases, the pathogenic determinants that are most responsible for causing the diseased condition may be similar (such as enzymes, toxins, etc.), resulting in very similar modes of action that alter human metabolic processes to produce identical biomarker metabolites.

Table 2. Volatile biomarker compounds in the human breath that are associated with the presence of multiple specific diseases, genetic disorders or adverse physiological conditions in the body.

\begin{tabular}{|c|c|c|c|}
\hline Biomarker Compounds ${ }^{1}$ & Chemical Structure & $\begin{array}{l}\text { Associated Diseases/ } \\
\text { Disorders/Conditions }{ }^{2}\end{array}$ & References \\
\hline \multirow{2}{*}{ Acetaldehyde } & & AFDL & {$[46]$} \\
\hline & & URTI & [37] \\
\hline \multirow{2}{*}{$\begin{array}{l}\text { Acetoin } \\
\text { (3-hydroxy-2-butanone) }\end{array}$} & & Lung cancer & {$[47]$} \\
\hline & & NSCLC & [47] \\
\hline \multirow{9}{*}{ Acetone } & & ARDS & {$[48,49]$} \\
\hline & & Lung cancer & {$[50]$} \\
\hline & & CIP & {$[48]$} \\
\hline & & CPD & {$[51]$} \\
\hline & & Cystic fibrosis & {$[52]$} \\
\hline & $-\mathrm{CH}_{3}$ & Diabetes mellitus & {$[41,53]$} \\
\hline & & Hepatic cirrhosis & {$[54]$} \\
\hline & & Ketosis, starvation & {$[55]$} \\
\hline & & PLC & [43] \\
\hline \multirow{10}{*}{$\begin{array}{l}\text { Alkanes, short-chain HC } \\
\text { (e.g., ethane) }\end{array}$} & \multirow{10}{*}{$\mathrm{H}_{3} \mathrm{C}-\mathrm{CH}_{3}$} & AHI & {$[56]$} \\
\hline & & Asthma & {$[57-59]$} \\
\hline & & COPD & {$[60]$} \\
\hline & & Cystic fibrosis & {$[52,61]$} \\
\hline & & IBD & {$[62-65]$} \\
\hline & & IHD, angina & {$[66,67]$} \\
\hline & & ILD & {$[68,69]$} \\
\hline & & Lung cancer & {$[66,70,71,72]$} \\
\hline & & Oxidative stress & {$[73]$} \\
\hline & & Schizophrenia & {$[74-76]$} \\
\hline
\end{tabular}


Table 2. Cont.

\begin{tabular}{|c|c|c|c|}
\hline Biomarker Compounds ${ }^{1}$ & Chemical Structure & $\begin{array}{l}\text { Associated Diseases/ } \\
\text { Disorders/Conditions }{ }^{2}\end{array}$ & References \\
\hline \multirow{2}{*}{ 1-Butanol } & & Lung cancer & {$[47]$} \\
\hline & & NSCLC & [47] \\
\hline \multirow{2}{*}{ Carbon disulfide } & & Cystic fibrosis & {$[52,77]$} \\
\hline & & Schizophrenia & [74-76] \\
\hline \multirow{6}{*}{ Dimethyl sulfide } & & Lung cancer & {$[78]$} \\
\hline & & Chronic hepatitis & [79] \\
\hline & & Cystic fibrosis & {$[52,77]$} \\
\hline & & Endocarditis (infective) & {$[80-83]$} \\
\hline & & Hepatic cirrhosis & {$[79,84-86]$} \\
\hline & & Hepatic coma & {$[79,86,87]$} \\
\hline \multirow{3}{*}{ Ethanol } & & CPD & {$[51]$} \\
\hline & & Cystic fibrosis & {$[52]$} \\
\hline & & Diabetes mellitus & {$[41,53]$} \\
\hline \multirow[b]{2}{*}{ Hydrogen sulfide } & & Endocarditis (infective) & [80-83] \\
\hline & & Hepatic cirrhosis & {$[84]$} \\
\hline \multirow{7}{*}{ Isoprene } & & AFDL & {$[46]$} \\
\hline & & ARDS & {$[48,49]$} \\
\hline & & Asthma & [57-59] \\
\hline & & CIP & [48] \\
\hline & & Cystic fibrosis & {$[52,88]$} \\
\hline & & Lung cancer & {$[50]$} \\
\hline & & PLC & {$[43]$} \\
\hline \multirow{3}{*}{$\begin{array}{l}\text { 8-Isoprostane } \\
\text { (8} 8 \text {-prostane) }\end{array}$} & & Asthma & [89] \\
\hline & & COPD & {$[90]$} \\
\hline & & Oxidative stress & [89] \\
\hline \multirow{3}{*}{ Leukotriene B4 } & & Asthma & {$[91,92]$} \\
\hline & & COPD & {$[90]$} \\
\hline & & Cystic fibrosis & {$[93]$} \\
\hline \multirow{2}{*}{ Methanol } & $\mathrm{H}_{3} \mathrm{C}$ & Cystic fibrosis & {$[52]$} \\
\hline & & Lung cancer & {$[50]$} \\
\hline \multirow{2}{*}{ Methyl nitrate } & & Diabetes mellitus & {$[41,53]$} \\
\hline & 0 & Hyperglycemia & {$[41,42]$} \\
\hline \multirow{4}{*}{$\begin{array}{l}\text { Methylated alkanes } \\
\text { (e.g., 2-methylpropane) }\end{array}$} & & Breast cancer & [94] \\
\hline & & IHD, angina & {$[66,67]$} \\
\hline & & Lung cancer & {$[66,70]$} \\
\hline & & Oxidative stress & {$[73]$} \\
\hline
\end{tabular}


Table 2. Cont.

\begin{tabular}{|c|c|c|c|}
\hline Biomarker Compounds ${ }^{1}$ & Chemical Structure & $\begin{array}{l}\text { Associated Diseases/ } \\
\text { Disorders/Conditions }{ }^{2}\end{array}$ & References \\
\hline \multirow{4}{*}{ Methyl-mercaptan } & \multirow{4}{*}{$\mathrm{H}_{3} \mathrm{C}-\mathrm{SH}$} & Chronic hepatitis & [79] \\
\hline & & Endocarditis (infective) & {$[80-83]$} \\
\hline & & Hepatic cirrhosis & {$[79,86]$} \\
\hline & & Hepatic coma & {$[79,86,87]$} \\
\hline \multirow{2}{*}{ Nitric oxide } & \multirow{2}{*}{$\mathrm{O}=\mathrm{N}$} & Asthma & [95] \\
\hline & & COPD & [96] \\
\hline \multirow{2}{*}{ Nitrotyrosine } & & COPD & [97] \\
\hline & & Cystic fibrosis & {$[97]$} \\
\hline \multirow{9}{*}{ Pentane } & & AHI & {$[56]$} \\
\hline & & ARDS & {$[48,49]$} \\
\hline & & Asthma & [57-59] \\
\hline & & CIP & {$[48]$} \\
\hline & & Cystic fibrosis & [52] \\
\hline & & IBD & {$[62-65]$} \\
\hline & & Lung cancer & [98] \\
\hline & & Rheumatoid arthritis & [99] \\
\hline & & Schizophrenia & {$[74-76]$} \\
\hline \multirow[t]{2}{*}{ Propane } & & Cystic fibrosis & {$[52]$} \\
\hline & & IBD & [62-65] \\
\hline \multirow{2}{*}{ o-Toluidine } & & Lung cancer & {$[100]$} \\
\hline & & PLC & [43] \\
\hline
\end{tabular}

\footnotetext{
${ }^{1}$ Biomarker compounds listed are VOCs that have been associated with specific diseases, metabolic disorders or adverse physiological conditions, although further independent research may be required to determine the strength of the correlation based on the incidence of these biomarker VOCs in the human breath relative to the presence of the indicated ailments. ${ }^{2}$ Disease abbreviations: AFDL $=$ alcoholic fatty liver disease; $\mathrm{AHI}=$ alcoholinduced hepatic injury; ARDS $=$ acute respiratory stress syndrome; CIP $=$ critically ill patients; $\mathrm{CPD}=$ cardiopulmonary disease; $\mathrm{COPD}=$ chronic obstructive pulmonary disease; $\mathrm{IBD}=$ inflammatory bowel disease; IHD $=$ ischemic heart disease; ILD $=$ interstitial lung disease (includes cryptogenic organizing pneumonia, idiopathic pulmonary fibrosis, sarcoidosis, etc.); PLC = primary lung cancer; NSCLC = non-small cell lung cancer; URTI $=$ upper respiratory tract infection.
}

Certain volatile biomarkers, such as acetone, certain alkanes, dimethyl sulfide, isoprene, methyl mercaptan and, pentane tend to be produced in response to a number of different diseases, suggesting a commonality of effects on the same human metabolic processes by virtue of the fact that only certain metabolic pathways are responsible for producing each of these biomarkers. As a result, the presence of these specific biomarkers in the human breath may be good general indicators of a diseased condition in the body and prompt further diagnostic investigations to find out the specific disease involved among those most associated with particular biomarkers. 


\section{Applications of Biomarker Detection in Disease Diagnosis}

The applied science area involving the use of metabolite biomarkers (metabolomics) in disease detection and diagnosis is still at an early stage of development; however, this approach is gaining increasing interest and will likely continue to progress toward developing standardized diagnostic methods for point-of-care clinical applications using e-nose-type devices that sense complex mixtures of abnormal volatile biomarkers in the breath of patients. Progress toward this goal will be facilitated by the identification and confirmation of new breath biomarker mixtures, defined as specific electronic breath signature patterns, as strong indicators of specific diseases in the body.

\subsection{Conventional Methods of Biomarker Detection}

Traditional analytical methods for the detection and identification of VOCs in metabolomic studies, including such instruments as gas chromatography-mass spectroscopy (GC-MS), nuclear magnetic resonance (NMR) and infrared spectroscopy (IR), are now supported by other new analytical methods. Human breath analysis now employs newer devices to identify breath biomarkers, including proton transfer reaction MS (PTRMS) [101], selected ion flow tube mass spectrometry (SIFT-MS) [102] and high-sensitivity laser spectroscopic techniques, including tunable diode laser absorption spectroscopy (TDLAS), cavity ringdown spectroscopy (CRDS), integrated cavity output spectroscopy (ICOS), cavityenhanced absorption spectroscopy (CEAS), cavity leak-out spectroscopy (CALOS), photoacoustic spectroscopy (PAS), quartz-enhanced photoacoustic spectroscopy (QEPAS) and optical frequency comb cavity-enhanced absorption spectroscopy (OFC-CEAS) [103]. Unfortunately, these time-consuming and very technical analytical methods are useful only for identifying individual compounds in breath metabolite mixtures, but are not so useful for identifying complex breath mixtures (breath sample signatures) as a whole that may contain many biomarkers of disease. These are the reasons why simpler, easier to use electronic devices, such as e-noses, will likely be used in the future to simultaneously detect complex mixtures of breath biomarkers more useful for diagnostic disease detection.

\subsection{Electronic-Nose Technologies for Biomarker Detection}

The utilization of e-nose instruments in metabolomics primarily involves the detection of complex volatile mixtures of biomarkers in the breath, which are analyzed as digital breath patterns that can be recognized via application-specific databases and correlated with the presence of specific diseases in associated organs or compartments of the body. Some examples where e-nose devices have been utilized in various studies conducted in research hospitals and universities worldwide to detect specific lung diseases from breath analyses are presented in Table 3. Most of these studies have involved large numbers of patients, several different e-nose instrument types and variable numbers of sensors in the sensor arrays for the detection of some important lung and heart diseases, including acute respiratory stress syndrome (ARDS), asthma, cancer, chronic obstructive pulmonary disease (COPD), endocarditis, malignant pleural mesothelioma (MPM), pulmonary tuberculosis (TB), upper respiratory tract infections (URTI) and ventilator-associated pneumonia (VAP). In most cases, e-nose devices have been quite effective at detecting specific diseases from breath analyses and at distinguishing between different diseases detected based on differences in breath signature patterns resulting from variations in volatile biomarker compounds found in patients' breath samples. 
Table 3. Studies utilizing electronic-nose instruments to detect aroma profiles containing volatile biomarker compounds as indicators of disease in the human breath, exhaled breath condensate, bronchi, or alveolar air.

\begin{tabular}{|c|c|c|c|c|c|}
\hline $\begin{array}{l}\text { Disease Detection/ } \\
\text { Discrimination }^{1} \\
\end{array}$ & Organ & $N^{2}$ & Study Locations ${ }^{3}$ & $\begin{array}{l}\text { E-Nose Type/ } \\
\text { No. Sensors }{ }^{4} \\
\end{array}$ & References \\
\hline ARDS-MPM & Lung & 78 & St. Vincent and Price of Wales Hospital, Sydney, Australia & $\mathrm{CP} 32$ & {$[104]$} \\
\hline \multirow{2}{*}{ Asthma } & \multirow{2}{*}{ Lung } & 40 & Leiden University MC, Leiden, the Netherlands & CP 32 & [105] \\
\hline & & 51 & Instituto Dermopatico deli' Immacolata, Rome, Italy & QMB 8 & [106] \\
\hline \multirow{3}{*}{ Asthma-COPD } & \multirow{3}{*}{ Lung } & 90 & $\begin{array}{l}\text { Academic MC Amsterdam, Haga Teaching Hospital, The Hague; } \\
\text { Albert Schweitzer Hospital, Dordrech, the Netherlands }\end{array}$ & $\mathrm{CP} 32$ & [107] \\
\hline & & 100 & $\begin{array}{l}\text { Academic MC Amsterdam, Haga Teaching Hospital, The Hague; } \\
\text { Albert Schweitzer Hospital, Dordrech, the Netherlands }\end{array}$ & $\mathrm{CP} 32$ & [108] \\
\hline & & 44 & University of New South Wales, Sydney, Australia & $\mathrm{CP} 32$ & [109] \\
\hline \multirow{5}{*}{ Cancer } & \multirow{5}{*}{ Lung } & 62 & C. Forlanini Hospital, Rome, Italy & QMB 8 & [71] \\
\hline & & 135 & Cleveland Clinic, Ohio, USA & $\mathrm{CP} 32$ & [110] \\
\hline & & 143 & Cleveland Clinic, Ohio, USA & CM 36 & [111] \\
\hline & & 92 & C. Forlanini Hospital, Rome, Italy & QMB 8 & [112] \\
\hline & & 229 & Cleveland Clinic, Ohio, USA & CM 36 & [113] \\
\hline COPD & Lung & 43 & Phillipps University, Marburg, Germany & CP 32 & [114] \\
\hline COPD-Cancer & Lung & 30 & Leiden University MC, Leiden, the Netherlands & CP 32 & [115] \\
\hline Endocarditis (infective) & Heart & 78 & Osaka University, Osaka, Japan. & MOS 6 & [116] \\
\hline IPA & Lung & 53 & University of Amsterdam, Amsterdam, The Netherlands & CP 32 & [117] \\
\hline MPM & Lung & 39 & University of Bari Aldo Moro, Bari, Italy & $\mathrm{CP} 32$ & [118] \\
\hline Pneumonia & Lung & 400 & Dept. of Anesthesia, University of Pennsylvania, Philadelphia, PA, USA & BS & [119] \\
\hline
\end{tabular}


Table 3. Cont.

\begin{tabular}{|c|c|c|c|c|c|}
\hline $\begin{array}{l}\text { Disease Detection/ } \\
\text { Discrimination }{ }^{1}\end{array}$ & Organ & $N^{2}$ & Study Locations ${ }^{3}$ & $\begin{array}{l}\text { E-Nose Type/ } \\
\text { No. Sensors }{ }^{4}\end{array}$ & References \\
\hline \multirow{2}{*}{$\mathrm{TB}$} & \multirow{2}{*}{ Lung } & 46 & Cranfield University, Silsoe, Bedfordshire, UK & CP 14 & [120] \\
\hline & & 134 & Cranfield University, Silsoe, Bedfordshire, UK & CP 14 & [121] \\
\hline \multirow[t]{2}{*}{ VAP } & \multirow[t]{2}{*}{ Lung } & 38 & University of Pennsylvania, Philadelphia, Pennsylvania, USA & $\mathrm{CP} 32$ & [119] \\
\hline & & 44 & University of Pennsylvania, Philadelphia, Pennsylvania, USA & CP 32 & [125] \\
\hline
\end{tabular}

${ }^{1}$ Abbreviations: ARDS = Acute Respiratory Stress Syndrome; COPD = Chronic Obstructive Pulmonary Disease; IPA = Invasive Pulmonary Aspergillosis; MPM = Malignant Pleural Mesothelioma; TB = pulmonary Tuberculosis; URTI Upper Respiratory Tract Infections); VAP = Ventilator Associated Pneumonia; ${ }^{2}$ Sample size collected from individual patients; NS = not specified; ${ }^{3}$ Hospital or university location where the study was conducted; ${ }^{4}$ Electronic-nose instrument type and number of sensors utilized in the e-nose sensor array for detection of lung diseases through analysis of human-breath signature patterns. BS = biosensor (experimental technology); $\mathrm{CM}=$ calorimetric; $\mathrm{CP}$ = conducting polymer; $\mathrm{MOS}$ = metal oxide semiconductors; $\mathrm{QMB}=$ quartz microbalance; $\mathrm{SAW}=$ surface acoustic wave. 
The electronic nose devices used in the experimental and clinical trials of the studies listed here were predominately conducted with polymer-type e-noses with 32 sensors in the sensor array. Conducting polymers are low power-consuming instruments with very good sensitivity and reproducibility (precision) at near room temperatures, but they have some disadvantages, including high sensor sensitivity to moisture, inactivation by certain strongly-polar analytes and relatively low sensor life (compared to MOS sensors) that tend to have a much longer sensor life, but operate at higher temperatures and with greater power demand. CP-sensors and some types of MOS sensors also sometimes exhibit problems of sensor compatibility and uniformity. QMB and SAW sensors have very good sensitivity, but are not as easily effective for the development of breathprints that can be stored in reference databases for comparisons and analysis of new sample unknowns, primarily due to the lack of available statistical software utilities with pattern recognition algorithms.

\section{Conclusions and Future Prospects}

The human breath is an obvious medium for point-in-time or continuous sampling and analysis of VOCs generated within the body, because these volatile compounds travel through the body via the circulatory system in the blood, cross the alveolar interface and are released in exhaled breath [126]. Analysis of VOCs in the breath can provide an indicator of current metabolic status for establishing a patient's level of health and the existence of any diseased states. E-nose technologies have the capabilities of non-invasively and painlessly detecting diseases in their early stages, allowing for early treatments and usually more rapid recovery of patients from diseased states. Thus, the VOCs present in the exhaled breath are a potentially rich and powerful source of biomarkers for the effective e-nose detection and diagnosis of not only respiratory diseases, but also many other diseases in the body.

Breath fingerprint analysis, coupling the use of traditional chemical analysis methods to identify metabolites with new EAD technologies, offers promising progress with great potential for promoting non-invasive methods of diagnosing the disease states of clinical patients. New e-nose methods and algorithms to analyze complex mixtures of breath VOCs offer high sensitivity, accuracy, precision, low response time and low detection limits, which are desirable characteristics for the detection of VOCs in human breath. The need for the standardization of breath sample collection and analysis methods are among the key issues thwarting the full-scale introduction of breath tests into clinical practice [127].

The future outlook for continued progress in the improvement of biomarker breath analysis to facilitate the accuracy and effectiveness of disease diagnostics is encouraging given all of the potential advantages afforded by the continued development of new e-nose technologies to detect the many and varied metabolic breath signatures associated with specific diseases found in different compartments and organs of the human body. The popularity and global enthusiastic interests in the noninvasive "biomarker" approach to disease diagnostics, based on gas analysis of the human breath, will no doubt lead to great new strides and accomplishments as new biomarkers and biomarker mixtures are discovered and more firmly correlated with specific diseases localized in various organs of the body. Very recent research and reviews have confirmed that e-noses are effective at recognizing VOC profiles, such as in disease-specific breath-prints, to accurately diagnose different pulmonary diseases, including ARDS [128], cystic fibrosis (CF), COPD [129], VAP [130], asthma, lung cancer [131] and various respiratory tract infections [132]. 
The desired combination of the e-nose capabilities of specificity, selectivity, robustness in operation, reproducible sensor uniformity and long-life stability is not offered by current e-nose instruments for most disease-diagnostic applications [133]. These technologies currently are unable to identify individual compounds, although they may be used to compare samples to see whether they have similar VOC profiles. VOC profiles or breathprints may be sufficient for diagnostic purposes in some respiratory diseases without having to identify individual compounds present in exhaled breath.

There is a need to build world-wide diagnostic biomarker databases for disease diagnosis, and associated clinical applications will facilitate the use of e-nose technologies for diagnostic applications in universal healthcare facilities, as well as for remote care applications using portable e-nose devices coupled with satellite uplinks and wireless Internet communication systems in order to access healthcare professionals in hospitals.

The need for dedicated application-specific e-noses combined with specialized databases for the diagnosis of specific disease categories should significantly improve and standardize the methods used by physicians to diagnose specific types and categories of diseases based on VOCs in patients' breath.

Future improvements of e-nose instruments, allowing the identification of biomarkers in breathprints, via interfacing e-noses in tandem with mass spectrometers or other analytical devices, may facilitate disease diagnoses in some cases, although better correlations of diagnostic disease biomarker mixtures in unique breathprints to specific diseases will go a long way toward making the use of e-nose technologies a well-established reality in point-of-care clinical diagnosis.

Miniaturization of e-nose technologies using fewer sensors, smart selection of sensor types used in the sensor array and improved pattern recognition algorithms designed specifically to recognize unique breathprints, based on the presence of disease-specific mixtures of biomarkers, so that analyses can become more accurate, dependable and unequivocal, results in delivering effective early diagnoses of organ-specific diseases from breath analysis of patients during routine annual noninvasive checkups involving simple breath tests, rather than invasive biopsies or painful procedures, such as mammograms and colonoscopies.

\section{Acknowledgments}

The author thanks Mrs. Charisse Oberle for help in collecting references, proofreading manuscript drafts and checking for any formatting and grammatical errors prior to submission. The author also thanks Prof. Dr. Jörg Ingo Baumbach (Reutlingen University, Faculty Applied Chemistry, Germany) for the invitation and opportunity to produce this international review article summarizing current research on the development of electronic-nose technologies for applications in the detection of volatile biomarkers in the human breath.

\section{Author Contributions}

All of the content in this paper was conceived of and developed by the sole author based on personal reviews and a synthesis of information from reference materials cited in this article.

\section{Conflicts of Interest}

The author declares no conflicts of interest in the preparation of this paper. 


\section{References}

1. Singeap, A.M.; Trifan, A.; Cojocariu, C.; Stanciu, C. Colon capsule endoscopy compared to colonoscopy for colorectal neoplasms diagnosis: An initial experience and a brief review of the literature. Rev. Med. Chir. Soc. Med. Nat. Iasi 2012, 116, 145-149.

2. Brandman, S.; Ko, J.P. Pulmonary nodule detection, characterization, and management with multidetector computed tomography. J. Thorac. Imaging 2011, 26, 90-105.

3. Hochhegger, B.; Marchiori, E.; Sedlaczek, O.; Irion, K.; Heussel, C.P.; Ley, S.; Ley-Zaporozhan, J.; Soares, S.A.J.; Kauczor, H.U. MRI in lung cancer: A pictorial essay. Br. J. Radiol. 2011, 84, 661-668.

4. Apantaku, L.M. Breast cancer diagnosis and screening. Am. Fam. Phys. 2000, 62, 596-602.

5. Truong, M.T.; Viswanathan, C.; Erasmus, J.J. Positron emission tomography/computed tomography in lung cancer staging, prognosis and assessment of therapeutic response. J. Thorac. Imaging 2011, $26,132-146$.

6. Hunt, K.K.; Newman, L.A.; Copeland, E.M.; Bland, K.I. The Breast. In Schwart'z Principles of Surgery, 9th ed.; Brunicardi, F., Andersen, D., Billiar, T., Eds.; McGraw-Hill: New York, NY, USA, 2011; pp. 791-796.

7. Todd, J.; McGrath, E.E. Chest X-ray mass in a patient with lung cancer! QJM 2011, 104, 903-904.

8. Wilson, A.D.; Baietto, M. Advances in electronic-nose technologies developed for biomedical applications. Sensors 2011, 11, 1105-1176.

9. Wilson, A.D.; Baietto, M. Applications and advances in electronic-nose technologies. Sensors 2009, 9, 5099-5148.

10. Kybert, N.J.; Egan, L.; Waldman, R.Z.; Zeng, X.-N.; Krein, M.; Preti, G.; Stuart, J.A.; Johnson, A.T.C. Analysis of sweat simulant mixtures using multiplexed arrays of DNA-carbon nanotube vapor sensors. J. Forensic Sci. Criminol. 2014, 1, 1-6.

11. Wilson, A.D. Diverse applications of electronic-nose technologies in agriculture and forestry. Sensors 2013, 13, 2295-2348.

12. Haick, H.; Broza, Y.Y.; Mochalski, P.; Ruzsanyi, V.; Amann, A. Assessment, origin, and implementation of breath volatile cancer markers. Chem. Soc. Rev. 2014, 43, 1423-1449.

13. Phillips, M.; Cataneo, R.N.; Chaturvedi, A.; Kaplan, P.D.; Libardoni, M.; Mundada, M.; Patel, U.; Zhang, X. Detection of an extended human volatome with comprehensive two-dimensional gas chromatography time-of-flight mass spectrometry. PLoS One 2013, 8, e75274.

14. Španěl, P.; Smith, D. On-line measurement of the absolute humidity of air, breath and liquid headspace samples by selected ion flow tube mass spectrometry. Rapid Commun. Mass Spectrom. 2001, 15, 563-569.

15. Smith, D.; Turner, C.; Španěl, P. Volatile metabolites in the exhaled breath of healthy volunteers: Their levels and distributions. J. Breath Res. 2007, 1, 1-12.

16. Diskin, A.M.; Španěl, P.; Smith, D. Time variation of ammonia, acetone, isoprene and ethanol in breath: A quantitative SIFT-MS study over 30 days. Physiol. Meas. 2003, 24, 107-119.

17. Turner, C.; Španěl, P.; Smith, D. A longitudinal study of methanol in the exhaled breath of 30 healthy volunteers using selected ion flow tube mass spectrometry, SIFT-MS. Physiol. Meas. 2006, 27, 637-648. 
18. Turner, C.; Španěl, P.; Smith, D. A longitudinal study of ammonia, acetone and propanol in the exhaled breath of 30 subjects using selected ion flow tube mass spectrometry, SIFT-MS. Physiol. Meas. 2006, 27, 321-337.

19. Turner, C.; Španěl, P.; Smith, D. A longitudinal study of breath isoprene in healthy volunteers using selected ion flow tube mass spectrometry (SIFT-MS). Physiol. Meas. 2006, 27, 13-22.

20. Turner, C.; Španěl, P.; Smith, D. A longitudinal study of ethanol and acetaldehyde in the exhaled breath of healthy volunteers using selected-ion flow-tube mass spectrometry. Rapid Commun. Mass Spectrom. 2006, 20, 61-68.

21. Anderson, J.C.; Babb, A.L.; Hlastala, M.P. Modeling soluble gas exchange in the airways and alveoli. Ann. Biomed. Eng. 2003, 31, 1402-1422.

22. King, J.; Koc, H.; Unterkofler, K.; Mochalski, P.; Kupferthaler, A.; Teschl, G.; Teschl, S.; Hinterhuber, H.; Amann, A. Physiological modeling of isoprene dynamics in exhaled breath. J. Theor. Biol. 2010, 267, 626-637.

23. King, J.; Unterkofler, K.; Teschl, G.; Teschl, S.; Koc, H.; Hinterhuber, H.; Amann, A. A mathematical model for breath gas analysis of volatile organic compounds with special emphasis on acetone. J. Math. Biol. 2011, 63, 959-999.

24. King, J.; Unterkofler, K.; Teschl, G.; Teschl, S.; Mochalski, P.; Koc, H.; Hinterhuber, H.; Amann, A. A modeling based evaluation of isothermal rebreathing for breath gas analysis of highly soluble volatile organic compounds. J. Breath Res. 2012, 6, 016005.

25. Kallioma ki, P.-L.; Korhonen, O.; Vaaranen, V.; Kallioma ki, K.; Koponen, M. Lung retention and clearance of shipyard arc welders. Int. Arch. Occup. Environ. Health 1978, 42, 83-90.

26. Jakubowski, M.; Czerczak, S. Calculating the retention of volatile organic compounds in the lung on the basis of their physicochemical properties. Environ. Toxicol. Pharmacol. 2009, 28, 311-315.

27. Buszewski, B.; Kesy, M.; Ligor, T.; Amann, A. Human exhaled air analytics: Biomarkers of diseases. Biomed. Chromatogr. 2007, 21, 553-566.

28. Halliwel, B. Free radicals, antioxidants, and human disease: Where are we now? J. Lab. Clin. Med. 1992, 119, 598-620.

29. Barr, D.D.; Wang, R.Y.; Needham, L.L. Biologic monitoring of exposure to environmental chemicals throughout the life stages: Requirements and issues for consideration for the National Children's Study. Environ. Health Perspect. 2005, 113, 1083-1091.

30. Schubert, J.K.; Miekisch, W.; Birken, T.; Geiger, K.; Noeldge-Schomburg, G. Impact of inspired substance concentrations on the results of breath analysis in mechanically ventilated patients. Biomarkers 2005, 10, 138-152.

31. Phillips, M.; Greenberg, J.; Sabas, M. Alveolar gradient of pentane in normal human breath. Free Radic. Res. 1994, 20, 333-337.

32. Miekisch, W.; Schubert, J.K.; Noeldge-Schomburg, G. Diagnostic potential of breath analysis_Focus on volatile organic compounds. Clin. Chim. Acta 2004, 347, 25-39.

33. Broza, Y.Y.; Haick, H. Nanomaterial-based sensors for detection of disease by volatile organic compounds. Nanomedicine 2013, 8, 785-806.

34. Deng, C.; Zhang, X.; Li, N. Investigation of volatile biomarkers in lung cancer blood using solid-phase microextraction and capillary gas chromatography-mass spectrometry. J. Chromatogr. B Biomed. Appl. 2004, 808, 269-277. 
35. Xue, R.; Dong, L.; Zhang, S.; Deng, C.; Liu, T.; Wang, J.; Shen, X. Investigation of volatile biomarkers in liver cancer blood using solid-phase microextraction and gas chromatography/mass spectrometry. Rapid Commun. Mass Spectrom. 2008, 22, 1181-1186.

36. Wilson, A.D. Chapter 15. Future Applications of Electronic-Nose Technologies in Healthcare and Biomedicine. In Wide Spectra of Quality Control; Akyar, I., Ed.; InTech: Rijeka, Croatia, 2011; pp. 267-290.

37. Filipiak, W.; Sponring, A.; Baur, M.M.; Ager, C., Filipiak, A.; Wiesenhofer, H.; Nagl, M.; Troppmair, J.; Amann, A. Characterization of volatile metabolites taken up by or released from Streptococcus pneumoniae and Haemophilus influenzae by using GC-MS. Microbiology 2012, 158, 3044-3053.

38. Bondy, P.K.; Rosenberg, L.E. Metabolic Control and Disease, 8th ed.; W.B. Sanders: Philadelphia, PA, USA, 1980; pp. 1010-1014.

39. Chambers, S.T.; Syhre, M.; Murdoch, D.R.; McCartin, F.; Epton, M.J. Detection of 2-pentylfuran in the breath of patients with Aspergillus fumigatus. Med. Mycol. 2009, 47, 468-476.

40. Milne, M.D. Disorders of amino-acid transport. Brit. Med. J. 1964, 1, 327-336.

41. Novak, B.J.; Blake, D.R.; Meinardi, S.; Rowland, F.S.; Pontello, A.; Cooper, D.M.; Galassetti, P.R. Exhaled methyl nitrate as a noninvasive marker of hyperglycemia in type 1 diabetes. Proc. Nat. Acad. Sci. 2007, 104, 15613-15618.

42. Lee, J.; Ngo, J.; Blake, D.; Meinardi, S.; Pontello, A.M.; Newcomb, R.; Galassetti, P.R. Improved predictive models for plasma glucose estimation from multi-linear regression analysis of exhaled volatile organic compounds. J. Appl. Physiol. 2009, 107, 155-160.

43. Wehinger, A.; Schmid, A.; Mechtcheriakov, S.; Ledochowski, M.; Grabmer, C.; Gastl, G.A.; Amanng, A. Lung cancer detection by proton transfer reaction mass-spectrometric analysis of human breath gas. Int. J. Mass. Spectrom. 2007, 265, 49-59.

44. Syhre, M.; Manning, L.; Phuanukoonnon, S.; Harino, P.; Chambers, S.T. The scent of Mycobacterium tuberculosis-part II breath. Tuberculosis 2009, 89, 263-266.

45. Sidbury, J.B.; Smith, E.K.; Harlan, W. An inborn error of short-chain fatty acid metabolism: The odor of sweaty feet syndrome. J. Pediatr. 1967, 70, 8-15.

46. Netzer, M.; Millonig, G.; Osl, M.; Pfeifer, B.; Praun, S.; Villinger, J.; Vogel, W.; Baumgartner, C. A new ensemble-based algorithm for identifying breath gas marker candidates in liver disease using ion molecule reaction mass spectrometry. Bioinformatics 2009, 25, 941-947.

47. Song, G.; Qin, T.; Liu, H.; Xu, G.B.; Pan, Y.Y.; Xiong, F.X.; Gu, K.S.; Sun, G.P.; Chen, Z.D. Quantitative breath analysis of volatile organic compounds of lung cancer patients. Lung Cancer 2010, 67, 227-231.

48. Scholpp, J.; Schubert, J.K.; Miekisch, W.; Geiger, K. Breath markers and soluble lipid peroxidation markers in critically ill patients. Clin. Chem. Lab. Med. 2002, 40, 587-594.

49. Schubert, J.K.; Muller, W.P.; Benzing, A.; Geiger, K. Application of a new method for analysis of exhaled gas in critically ill patients. Intensive Care Med. 1998, 24, 415-421.

50. Bajtarevic, A.; Ager, C.; Pienz, M.; Klieber, M.; Schwarz, K.; Ligor, M.; Ligor, T.; Filipiak, W.; Denz, H.; Fiegl, M.; et al. Noninvasive detection of lung cancer by analysis of exhaled breath. BMC Cancer 2009, 9, 348-364. 
51. Skrupskii, V.A. Gas chromatographic analysis of ethanol and acetone in the air exhaled by patients. Clin. Lab. Diagn. 1995, 4, 35-38.

52. Barker, M.; Hengst, M.; Schmid, J.; Buers, H.J.; Mittermaier, B.; Klemp, D.; Koppmann, R. Volatile organic compounds in the exhaled breath of young patients with cystic fibrosis. Eur. Respir. J. 2006, 27, 929-936.

53. Ping, W.; Yi, P.; Haibao, X.; Farange, S. A novel method for diabetes diagnosis based on electronic nose. Biosens. Bioelectron. 1997, 12, 1031-1036.

54. Van den Velde, S.; Nevens, F.; van Hee, P.; van Steenberghe, D.; Quirynen, M. GC-MS analysis of breath odor compounds in liver patients. J. Chromatogr. B 2008, 875, 344-348.

55. Likhodii, S.S.; Musa, K.; Cunnane, S.C. Breath acetone as a measure of systemic ketosis assessed in a rat model of the ketogenic diet. Clin. Chem. 2002, 48, 115-120.

56. Lettéron, P.; Duchatelle, V.; Berson, A.; Fromenty, B.; Fisch, C.; Degott, C.; Benhamou, J.P.; Pessayre, D. Increased ethane exhalation, an in vivo index of lipid peroxidation, in alcohol-abusers. Gut 1993, 34, 409-414.

57. Olopade, C.O.; Zakkar, M.; Swedler, W.I.; Rubinstein, I. Exhaled pentane levels in acute asthma. Chest 1997, 111, 862-865.

58. Paredi, P.; Kharitonov, S.A.; Barnes, P.J. Elevation of exhaled ethane concentration in asthma. Am. J. Respir. Crit. Care Med. 2000, 162, 1450-1454.

59. Larstad, M.A.; Toren, K.; Bake, B.; Olin, A.C. Determination of ethane, pentane and isoprene in exhaled air-effects of breath-holding, flow rate and purified air. Acta Physiol. (Oxf.) 2007, 189, 87-98.

60. Paredi, P.; Kharitonov, S.A.; Leak, D.; Ward, S.; Cramer, D.; Barnes, P.J. Exhaled ethane, a marker of lipid peroxidation, is elevated in chronic obstructive pulmonary disease. Am. J. Respir. Crit. Care Med. 2000, 162, 369-373.

61. Paredi, P.; Kharitonov, S.A.; Leak, D.; Shah, P.L.; Cramer, D.; Hodson, M.E.; Barnes, P.J. Exhaled ethane is elevated in cystic fibrosis and correlates with carbon monoxide levels and airway obstruction. Am. J. Respir. Crit. Care Med. 2000, 161, 1247-1251.

62. Ondrula, D.; Nelson, R.L.; Andrianopoulos, G.; Schwartz, D.; Abcarian, H.; Birnbaum, A.; Skosey, J. Quantitative determination of pentane in exhaled air correlates with colonic inflammation in the rat colitis model. Dis. Colon. Rectum 1993, 36, 457-462.

63. Kokoszka, J.; Nelson, R.L.; Swedler, W.I.; Skosey, J.; Abcarian, H. Determination of inflammatory bowel disease activity by breath pentane analysis. Dis. Colon. Rectum 1993, 36, 597-601.

64. Sedghi, S.; Keshavarzian, A.; Klamut, M.; Eiznhamer, D.; Zarling, E.J. Elevated breath ethane levels in active ulcerative colitis: Evidence for excessive lipid peroxidation. Am. J. Gastroenterol. 1994, 89, 2217-2221.

65. Pelli, M.A.; Trovarelli, G.; Capodicasa, E.; de Medio, G.E.; Bassotti, G. Breath alkanes determination in ulcerative colitis and Crohn's disease. Dis. Colon. Rectum 1999, 42, 71-76.

66. Phillips, M.; Cataneo, R.N.; Cummin, A.R.; Gagliardi, A.J.; Gleeson, K.; Greenberg, J.; Maxfield, R.A.; Rom, W.N. Detection of lung cancer with volatile markers in the breath. Chest 2003, 123, 2115-2123.

67. Dobbelaar, P.; Mottram, T.T.; Nyabadza, C.; Hobbs, P.J.; Elliott-Martin, R.J.; Schukken, Y.H. Detection of ketosis in dairy cows by analysis of exhaled breath. Vet. Quart. 1996, 18, 151-152. 
68. Kanoh, S.; Kobayashi, H.; Motoyoshi, K. Exhaled ethane: An in vivo biomarker of lipid peroxidation in interstitial lung diseases. Chest 2005, 128, 2387-2392.

69. Dragonieri, S.; Brinkman, P.; Mouw, E.; Zwinderman, A.H.; Carratứ, P.; Resta, O.; Sterk, P.J.; Jonkers, R.E. An electronic nose discriminates exhaled breath of patients with untreated pulmonary sarcoidosis from controls. Respir. Med. 2013, 107, 1073-1078.

70. Phillips, M.; Gleeson, K.; Huges, J.M.B.; Greenberg, J.; Cataneo, R.N.; Baker, L.; McYay, W.P. Volatile organic compounds in breath as markers of lung cancer: A cross-sectional study. Lancet 1999, 353, 1930-1933.

71. Di Natale, C.; Macagnano, A.; Martinelli, E.; Paolesse, R.; D’Arcangelo, G.; Roscioni, C.; Finazzi-Agro, A.; D'Amico, A. Lung cancer identification by the analysis of breath by means of an array of non-selective gas sensors. Biosens. Bioelectron. 2003, 18, 1209-1218.

72. Skeldon, K.D.; McMillan, L.C.; Wyse, C.A.; Monk, S.D.; Gibson, G.; Patterson, C.; France, T.; Longbottom, C.; Padgett, M.J. Application of laser spectroscopy for measurement of exhaled ethane in patients with lung cancer. Respir. Med. 2006, 100, 300-306.

73. Hakim, M.; Broza, Y.Y.; Barash, O.; Peled, N.; Phillips, M.; Amann, A.; Haick, H. Volatile organic compounds of lung cancer and possible biochemical pathways. Chem. Rev. 2012, 112, 5949-5966.

74. Smith, K.; Sines, J. Demonstration of a peculiar odor in the sweat of schizophrenic patients. AMA Arch. Gen. Psych. 1960, 2, 184-188.

75. Smith, K.; Thompson, G.F.; Koster, H.D. Sweat in schizophrenic patients: Identification of the odorous substance. Science 1969, 166, 398-399.

76. Phillips, M.; Sabas, M.; Greenberg, J. Increased pentane and carbon disulphide in the breath of patients with schizophrenia. J. Clin. Pathol. 1993, 46, 861-864.

77. Kamboures, M.A.; Blake, D.R.; Cooper, D.M.; Newcomb, R.L.; Barker, M.; Larson, J.K.; Meinardi, S.; Nussbaum, E.; Rowland, F.S. Breath sulfides and pulmonary function in cystic fibrosis. Proc. Natl. Acad. Sci. USA 2005, 102, 15762-15767.

78. Kischkel, S.; Miekisch, W.; Sawacki, A.; Straker, E.M.; Trefz, P.; Amann, A.; Schubert, J.K. Breath biomarkers for lung cancer detection and assessment of smoking related effects-confounding variables, influence of normalization and statistical algorithms. Clin. Chim. Acta 2010, 411, 1637-1644.

79. Kaji, H.; Hisamura, M.; Saito, N.; Murao, M. Gas chromatographic determination of volatile sulphur compounds in expired alveolar air in hepatopathic patients. J. Chromatogr. 1978, 145, 464-468.

80. Van den Velde, S.; van Steenberghe, D.; van Hee, P.; Quirynen, M. Detection of odorous compounds in breath. J. Dent. Res. 2009, 88, 285-289.

81. Okell, C.C.; Elliott, S.D. Bacteraemia and oral sepsis with special reference to the aetiology of subacute endocarditis. Lancet 1935, 2, 869-872.

82. Drangsholt, M.T. A new causal model of dental diseases associated with endocarditis. Ann. Periodontol. 1998, 3, 184-196.

83. Lacassin, F.; Hoen, B.; Leport, C.; Selton-Suty, C.; Delahaye, F.; Goulet, V.; Etienne, J.; Briançon, S. Procedures associated with infective endocarditis in adults: A case-control study. Eur. Heart J. 1995, 16, 1968-1974.

84. Chen, S.; Mahadevan, V.; Zieve, L. Volatile fatty acids in the breath of patients with cirrhosis of the liver. J. Lab. Clin. Med. 1970, 75, 622-627. 
85. Van den Velde, S.; Nevens, F.; van Hee, P.; van Steenberghe, D.; Quirynen, M. GC-MS analysis of breath odor compounds in liver patients. J. Chromatogr. B 2008, 875, 344-348.

86. Kaji, H.; Hisamura, M.; Sato, N.; Murao, M. Evaluation of volatile sulfur compounds in the expired alveolar gas in patients with liver cirrhosis. Clin. Chim. Acta 1978, 85, 279-284.

87. Hisamura, M. Quantitative analysis of methyl mercaptan and dimethyl sulfide in human expired alveolar gas and its clinical application: Study in normal subjects and patients with liver diseases. Nippon Naika Gakkai Zasshi 1979, 68, 1284-1292.

88. McGrath, L.T.; Patrick, R.; Mallon, P.; Dowey, L.; Silke, B.; Norwood, W.; Elborn, S. Breath isoprene during acute respiratory exacerbation in cystic fibrosis. Eur. Respir. J. 2000, 16, 1065-1069.

89. Montuschi, P.; Corradi, M.; Ciabattoni, G.; Nightingale, J.; Kharitonov, S.A.; Barnes, P.J. Increased 8-isoprostane, a marker of oxidative stress, in exhaled condensate of asthma patients. Am. J. Respir. Crit. Care Med. 1999, 160, 216-220.

90. Borrill, Z.L.; Starkey, R.C.; Singh, S.D. Variability of exhaled breath condensate leukotriene B4 and 8-isoprostane in COPD patients. Int. J. Chron. Obstruct. Pulmon. Dis. 2007, 2, 71-76.

91. Kostikas, K.; Papatheodorou, G.; Psathakis, K.; Panagou, P.; Loukides, S. Prostaglandin E2 in the expired breath condensate of patients with asthma. Eur. Respir. J. 2003, 22, 743-747.

92. Kostikas, K.; Gaga, M.; Papatheodorou, G.; Karamanis, T.; Orphanidou, D.; Loukides, S. Leukotriene B4 in exhaled breath condensate and sputum supernatant in patients with COPD and asthma. Chest 2005, 127, 1553-1559.

93. Carpagnano, G.E.; Barnes, P.J.; Geddes, D.M.; Hodson, M.E.; Kharitonov, S.A. Increased leukotriene B4 and interleukin-6 in exhaled breath condensate in cystic fibrosis. Am. J. Resp. Crit. Care 2003, 167, 1109-1112.

94. Phillips, M.; Cataneo, R.N.; Ditkoff, B.A.; Fisher, P.; Greenberg, J.; Gunawardena, R.; Kwon, C.S.; Rahbari-Oskoui, F.; Wong, C. Volatiles markers of breast cancer in the breath. Breast J. 2003, 9, 184-191.

95. Smith, A.D.; Cowan, J.O.; Filsell, S.; McLachlan, C.; Monti-Sheehan, G.; Jackson, P.; Taylor, D.R. Diagnosing asthma: Comparisons between exhaled nitric oxide measurements and conventional tests. Am. J. Respir. Crit. Care Med. 2004, 169, 473-478.

96. Corradi, M.; Majori, M.; Cacciani, G.C.; Consigli, G.F.; de'Munari, E.; Pesci, A. Increased exhaled nitric oxide in patients with stable chronic obstructive pulmonary disease. Thorax 1999, 54, 572-575.

97. Balint, B.; Kharitonov, S.A.; Hanazawa, T.; Donnelly, L.E.; Shah, P.L.; Hodson, M.E.; Barnes, P.J. Increased nitrotyrosine in exhaled breath condensate in cystic fibrosis. Eur. Respir. J. 2001, 17, 1201-1207.

98. Crohns, M.; Saarelainen, S.; Laitinen, J.; Peltonen, K.; Alho, H.; Kellokumpu-Lehtinen, P. Exhaled pentane as a possible marker for survival and lipid peroxidation during radiotherapy for lung cancer - a pilot study. Free Radic. Res. 2009, 43, 965-974.

99. Humad, S.; Zarling, E.; Clapper, M.; Skosey, J.L. Breath pentane excretion as a marker of disease activity in rheumatoid arthritis. Free Radic. Res. Commun. 1988, 5, 101-106.

100. Preti, G.; Labows, J.N.; Kostelc, J.G.; Aldinger, S.; Daniele, R. Analysis of lung air from patients with bronchogenic carcinoma and controls using gas chromatography-mass spectrometry. J. Chromatogr. 1988, 432, 1-11. 
101. Ruzsanyi, V.; Fischer, L.; Herbig, J.; Ager, C.; Amann, A. Multi-capillary-column proton-transfer-reaction time-of-flight mass spectrometry. J. Chromatogr. A 2013, 1316, 112-118.

102. Španěl, P.; Smith, D. Progress in SIFT-MS: Breath analysis and other applications. Mass Spectrom. Rev. 2011, 30, 236-267.

103. Wang, C.; Sahay, P. Breath analysis using laser spectroscopic techniques: Breath biomarkers, spectral fingerprints, and detection limits. Sensors 2009, 9, 8230-8262.

104. Chapman, E.A.; Thomas, P.S.; Stone, E.; Lewis, C.; Yates, D.H. A breath test for malignant mesothelioma using an electronic nose. Eur. Respir. J. 2012, 40, 448-454.

105. Dragonieri, S.; Schot, R.; Mertens, B.J.; le Cessie, S.; Gauw, S.A.; Spanevello, A.; Resta, O.; Willard, N.P.; Vink, T.J.; Rabe, K.F.; et al. An electronic nose in the discrimination of patients with asthma and controls. J. Allergy Clin. Immunol. 2007, 120, 856-862.

106. Montuschi, P.; Santonico, M.; Mondino, C.; Pennazza, G.; Mantini, G.; Martinelli, E.; Capuano, R.; Ciabattoni, G.; Paolesse, R.; di Natale, C.; et al. Diagnostic performance of an electronic nose, fractional exhaled nitric oxide, and lung function testing in asthma. Chest 2010, 137, 790-796.

107. Fens, N.; Zwinderman, A.H.; van der Schee, M.P.; de Nijs, S.B.; Dijkers, E.; Roldaan, A.C.; Cheung, D.; Bel, E.H.; Sterk, P.J. Exhaled breath profiling enables discrimination of chronic obstructive pulmonary disease and asthma. Am. J. Respir. Crit. Care Med. 2009, 180, 1076-1082.

108. Fens, N.; Roldaan, A.C.; van der Schee, M.P.; Boksem, R.J.; Zwinderman, A.H.; Bel, E.H.; Sterk, P.J. External validation of exhaled breath profiling using an electronic nose in the discrimination of asthma with fixed airways obstruction and chronic obstructive pulmonary disease. Clin. Exp. Allergy 2011, 41, 1371-1378.

109. Timms, C.; Thomas, P.S.; Yates, D.H. Detection of gastro-oesophageal reflux disease (GORD) in patients with obstructive lung disease using exhaled breath profiling. J. Breath Res. 2012, 6, 016003.

110. Machado, R.F.; Laskowski, D.; Deffenderfer, O.; Burch, T.; Zheng, S.; Mazzone, P.J.; Mekhail, T.; Jennings, C.; Stoller, J.K.; Pyle, J.; et al. Detection of lung cancer by sensor array analyses of exhaled breath. Am. J. Respir. Crit. Care Med. 2005, 171, 1286-1291.

111. Mazzone, P.J.; Hammel, J.; Dweik, R.; Na, J.; Czich, C.; Laskowski, D.; Mekhail, T. Diagnosis of lung cancer by the analysis of exhaled breath with a colorimetric sensor array. Thorax 2007, 62, $565-568$.

112. D’Amico, A.; Pennazza, G.; Santonico, M.; Martinelli, E.; Roscioni, C.; Galluccio, G.; Paolesse, R.; Di Natale, C. An investigation on electronic nose diagnosis of lung cancer. Lung Cancer 2010, 68, 170-176.

113. Mazzone, P.J.; Wang, X.F.; Xu, Y.; Mekhail, T.; Beukemann, M.C.; Na, J.; Kemling, J.W.; Suslick, K.S.; Sasidhar, M. Exhaled breath analysis with a colorimetric sensor array for the identification and characterization of lung cancer. J. Thorac. Oncol. 2012, 7, 137-142.

114. Hattesohl, A.D.; Jorres, R.A.; Dressel, H.; Schmid, S.; Vogelmeier, C.; Greulich, T.; Noeske, S.; Bals, R.; Koczulla, A.R. Discrimination between COPD patients with and without alpha 1-antitrypsin deficiency using an electronic nose. Respirology 2011, 16, 1258-1264.

115. Dragonieri, S.; Annema, J.T.; Schot, R.; van der Schee, M.P.; Spanevello, A.; Carratu, P.; Resta, O.; Rabe, K.F.; Sterk, P.J. An electronic nose in the discrimination of patients with non-small cell lung cancer and COPD. Lung Cancer 2009, 64, 166-170. 
116. Tanaka, M.; Anguri, H.; Nonaka, A.; Kataoka, K.; Nagata, H.; Kita, J.; Shizukuishi, S. Clinical assessment of oral malodor by the electronic nose system. J. Dent. Res. 2004, 83, 317-321.

117. De Heer, K.; van der Schee, M.P.; Zwinderman, K.; van den Berk, I.A.H.; Visser, C.E.; van Oers, R.; Sterk, P.J. Invasive pulmonary aspergillosis in prolonged chemotherapy-induced neutropenia: A proof-of-principle study. J. Clin. Microbiol. 2013, 51, 1490-1495.

118. De Gennaro, G.; Dragonieri, S.; Longobardi, F.; Musti, M.; Stallone, G.; Trizio, L.; Tutino, M. Chemical characterization of exhaled breath to differentiate between patients with malignant pleural mesothelioma from subjects with similar professional asbestos exposure. Anal. Bioanal. Chem. 2010, 398, 3043-3050.

119. Hanson, C.W., III; Thaler, E.R. Electronic nose prediction of a clinical pneumonia score: Biosensors and microbes. Anesthesiology 2005, 102, 63-68.

120. Pavlou, A.; Magan, N.; Jones, J.; Brown, J.; Klatser, P.; Turner, A. Detection of Mycobacterium tuberculosis (TB) in vitro and in situ using an electronic nose in combination with a neural network system. Biosens. Bioelectron. 2004, 20, 538-544.

121. Fend, R.; Kolk, A.H.J.; Bessant, C.; Buijtels, P.; Klatser, P.R.; Woodman, A.C. Prospects for clinical application of electronic-nose technology to early detection of Mycobacterium tuberculosis in culture and sputum. J. Clin. Microbiol. 2006, 44, 2039-2045.

122. Phillips, M.; Basa-Dalay, V.; Blais, J.; Bothamley, G.; Chaturvedi, A.; Modi, K.D.; Pandya, M.; Natividad, M.P.; Patel, U.; Ramraje, N.N.; et al. Point-of-care breath test for biomarkers of active pulmonary tuberculosis. Tuberculosis 2012, 92, 314-320.

123. Lai, S.Y.; Deffenderfer, O.F.; Hanson, W.; Phillips, M.P.; Thaler, E.R. Identification of upper respiratory bacterial pathogens with the electronic nose. Laryngoscope 2002, 112, 975-979.

124. Hockstein, N.G.; Thaler, E.R.; Torigian, D.; Miller, W.T., Jr.; Deffenderfer, O.; Hanson, C.W. Diagnosis of pneumonia with an electronic nose: Correlation of vapor signature with chest computed tomography scan findings. Laryngoscope 2004, 114, 1701-1705.

125. Hockstein, N.G.; Thaler, E.R.; Lin, Y.; Lee, D.D.; Hanson, C.W. Correlation of pneumonia score with electronic nose signature: A prospective study. Ann. Otol. Rhinol. Laryngol. 2005, 114, 504-508.

126. Smith, D.; Španěl, P. The challenge of breath analysis for clinical diagnosis and therapeutic monitoring. Analyst 2007, 132, 390-396.

127. Wilson, A.D. Electronic-nose applications in forensic science and for analysis of volatile biomarkers in the human breath. J. Forensic Sci. Criminol. 2014, 1, 1-21.

128. Bos, L.D.J.; Schultz, M.J.; Sterk, P.J. Exhaled breath profiling for diagnosing acute respiratory distress syndrome. BMC Pulm. Med. 2014, 14, 72.

129. Shaw, J.G.; Vaughan, A.; Dent, A.G.; O’Hare, P.E.; Goh, F.; Bowman, R.V.; Fong, K.M.; Ian, A.; Yang, I.A. Biomarkers of progression of chronic obstructive pulmonary disease (COPD). J. Thorac. Dis. 2014, 6, 1532-1547.

130. Bos, L.D.J.; Martin-Loeches, I.; Kastelijn, J.B.; Gili, G.; Espasa, M.; Povoa, P.; Kolk, A.H.J.; Janssen, H.-G.; Sterk, P.J.; Artigas, A.; et al. The volatile metabolic fingerprint of ventilator-associated pneumonia. Intensive Care Med. 2014, 40, 761-776.

131. Bikov, A.; Hernadi, M.; Korosi, B.Z.; Kunos, L.; Zsamboki, G.; Sutto, Z.; Tarnoki, A.D.; Tarnoki, D.L.; Losonczy, G.; Horvath, I. Expiratory flow rate, breath hold and anatomic dead space influence electronic nose ability to detect lung cancer. BMC Pulm. Med. 2014, 14, 202. 
132. Van de Kant, K.D.; van der Sande, L.J.; Jöbsis, Q., van Schayck, O.C.; Dompeling, E. Clinical use of exhaled volatile organic compounds in pulmonary diseases: A systematic review. Respir. Res. 2012, 13, 117.

133. Lourenço, C.; Turner, C. Breath analysis in disease diagnosis: Methodological considerations and applications. Metabolites 2014, 4, 465-498.

(C) 2015 by the authors; licensee MDPI, Basel, Switzerland. This article is an open access article distributed under the terms and conditions of the Creative Commons Attribution license (http://creativecommons.org/licenses/by/4.0/). 